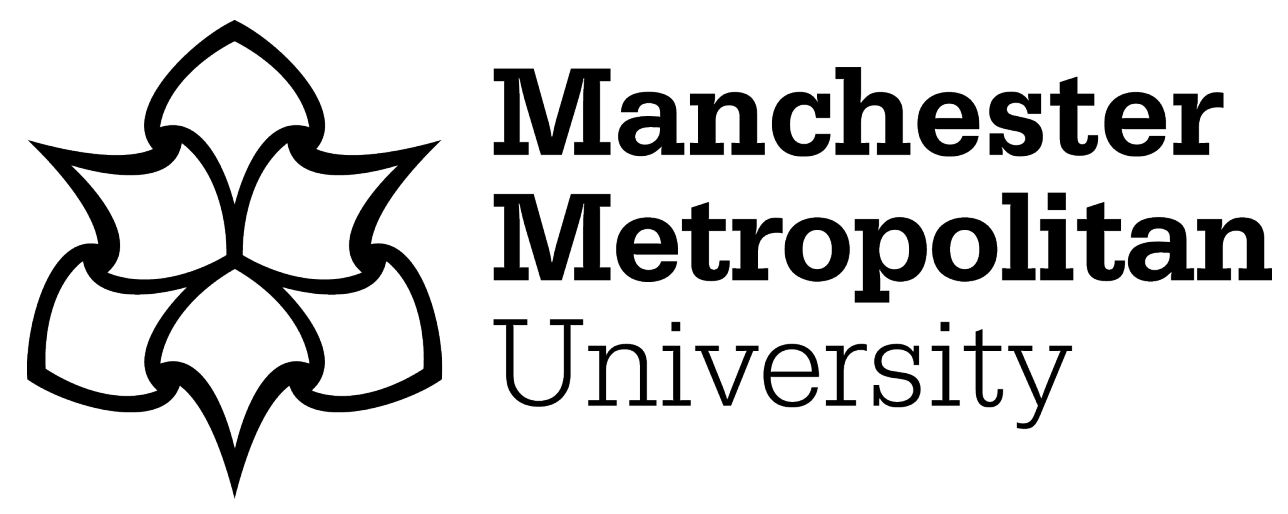

Kerrane, Benedict ORCID logoORCID: https://orcid.org/0000-0003-21145965, Kerrane, Katy, Bettany, Shona and Rowe, David (2021) (Invisible) Displays of Survivalist Intensive Motherhood among UK Brexit Preppers. Sociology, 55 (6). pp. 1151-1168. ISSN 0038-0385

Downloaded from: https://e-space.mmu.ac.uk/627535/

Version: Published Version

Publisher: SAGE Publications

DOI: https://doi.org/10.1177/0038038521997763

Usage rights: Creative Commons: Attribution 4.0

Please cite the published version 


\title{
(Invisible) Displays of Survivalist Intensive Motherhood among UK Brexit Preppers
}

\section{Ben Kerrane}

Manchester Metropolitan University, UK

\section{Katy Kerrane}

University of Liverpool, UK

\section{Shona Bettany}

University of Huddersfield, UK

\section{David Rowe}

University of Leeds, UK

\begin{abstract}
This article explores mothers' narratives of 'prepping' behaviours. Prepping involves the management of stockpiled household items in anticipation of marketplace disruption. In this article, we use anticipated food shortages following the UK's exit from the EU ('Brexit') as our context. Drawing on interview data, we highlight how mothers embed prepping into their ongoing pursuit of intensive motherhood, bound in the highly gendered practice of feeding the family. While adhering to elements of intensive motherhood ideology (their actions are labour intensive/child centred), participants reveal a hidden element to their practice. We introduce the notion of 'survivalist intensive motherhood' to understand their actions. Survivalist intensive motherhood departs from earlier intensive motherhood studies due to the largely invisible nature of preparations and the trade-offs made to feed the family during resource scarcity.
\end{abstract}

\section{Keywords}

Brexit, display, family, food, gender, intensive mothering, prepping, survival

\section{Corresponding author:}

Ben Kerrane, Manchester Metropolitan University Business School, Oxford Road, Manchester, MI5 6BH, UK. Email: b.kerrane@mmu.ac.uk 


\section{Introduction}

Intensive parenting represents a growing trend within parenting cultures (Cappellini et al., 2019). Although a gender-neutral term, studies of intensive parenting predominantly focus on mothers, given their primary care role (Shirani et al., 2012), bound in 'the day-to-day labour of nurturing the child, listening to the child, attempting to decipher the child's needs and desires, struggling to meet the child's wishes, and placing the child's well-being ahead of their own convenience' (Hays, 1996: 8). Intensive motherhood practices are, therefore, highly child-centric and necessitate the expenditure of time, love and money (Lee et al., 2010), requiring mothers 'not only to put their child's needs before their own in every respect, but to be able to display this to others through everyday practices' (Cappellini et al., 2019: 470). Motherhood - including the food mothers offer their children - is thus entwined in public display, highly visible and monitored by others (Finch, 2007). 'Good' or 'bad' moral accountabilities surrounding parenting permeate the practice of offering food to children, suffused with classed discourses of 'proper' and 'healthy' eating (Harman and Cappellini, 2015).

In this article, we depart from existing renderings of intensive motherhood by presenting a particular version of such practice: survivalist intensive motherhood. Using the context of mothers who identify as Brexit preppers (collecting food, water and medicine in anticipation of shortages and market disruption following Britain's exit from the European Union: 'Brexit') we demonstrate how some of the tenets of intensive motherhood, particularly public display and healthy food production/consumption, recede as mothering practices are framed around the survival of the family. The survivalist intensive mother, while adhering to norms of moral accountability and child-centredness, makes discontinuous trade-offs in her motherhood practice to ensure the well-being of her child and to maintain her identity as a 'good' mother in anticipated times of disruption. These trade-offs may well require a temporary departure from expert advice and acknowledged best practice (e.g. healthy eating), as well as requiring efforts to hide (rather than display) motherly prepping behaviours to ensure the safety of her family. Although Brexit prepping may well be viewed as an exceptional context, the precarious nature of supply-chains during unforeseen events (e.g. volatile weather patterns, natural disasters, pandemics) suggests this form of intensive motherhood may be more pervasive than expected. For example, one in five British consumers are reportedly stockpiling food, drink and medicines in preparation for a no-deal Brexit (The Guardian, 2019). Recent disruption during the COVID-19 pandemic (and resultant shortages of essential items, such as toilet paper) also demonstrates consumer propensity to stockpile when faced with disruption/uncertainty.

Prepping is usually undertaken by those preparing to independently survive disaster (Mills, 2019), linked to the delusional certainty of apocalyptic collapse among a marginal subculture, most commonly in the USA (e.g. doomsday preppers). Yet more recent research positions prepping as an increasingly mainstream precautionary tactic in response to some forms of crisis (Campbell et al., 2019; Mills, 2019). In relation to Brexit, UK consumers expressed particular anxieties regarding the availability of food and medical supplies (see Feng et al., 2017). This study examines how these anxieties manifest themselves within the family, and in particular, how mothers prepare for anticipated resource 
scarcity and marketplace disruption. We use the ideology of intensive motherhood (Hays, 1996) as our starting point to explore how moral discourses of good mothering and display shape mothers' lived experiences of Brexit prepping.

\section{Intensive Motherhood}

The concept of 'intensive mothering', developed by Hays (1996), highlights the experiences of contemporary mothers who are increasingly involved in the labour market, yet remain morally accountable for childrearing, leaving them feeling torn between the spheres of work and home (Faircloth and Gürtin, 2018). Within a wider context in which parenting has become more child-centric and expert guided, intensive mothering deems mothers ultimately responsible for all aspects of their child's development and future success (Hays, 1996; Miller, 2005; Wall, 2013). Parenting and child-development experts have expanded what constitutes the 'needs' of the child, from physical care, including foodwork, to 'emotional, psychological and cognitive needs' (Romagnoli and Wall, 2012: 273). Mothers are expected to spend prolonged one-to-one 'quality time' with children, which, childrearing experts claim, stimulates brain development (Wall, 2010). Despite little evidence to support these claims, mothers are deemed responsible for cultivating their child's future intellectual capabilities (Wall, 2010). Under intensive mothering, the child is viewed as sacred; raising a child is framed as one of the most fulfilling phases of a woman's life-course, and 'one of the most important things one can do for society' (Hays, 1996: 68). While recent discourses of fatherhood have shifted towards fathers becoming more actively involved in childcare (Dermott and Miller, 2015), and susceptible to 'intensive parenting' discourses (Shirani et al., 2012), they can opt-out of intensive parenting more easily than mothers, who largely remain targets for these cultural messages (Cappellini et al., 2019; Faircloth and Gürtin, 2018).

Sociological literature on mothering highlights how women present themselves as good mothers through their everyday practices of mothering, including feeding the family (DeVault, 1991; Harman and Cappellini, 2015). Family display is an important way in which people 'convey to each other and to relevant audiences that certain of their actions constitute "doing family things" and thereby confirm that these relationships are "family" relationships' (Finch, 2007: 67). Mothers are under pressure to perform 'display work', and internalise the need to display good mothering to the extent that they monitor themselves against the norms of intensive mothering (Budds et al., 2017). They feel surveilled by formal experts, professionals and during everyday encounters with other mothers (Dermott and Seymour, 2011; Henderson et al., 2010). Those differing from these norms risk displaying poor family practice and being judged as 'troublesome' (Harman and Cappellini, 2015) or 'bad' mothers (James and Curtis, 2010).

Research on motherhood and display highlights that intensive mothering is connected with social class, largely underpinned by middle-class values and dispositions (Kehily and Thomson, 2011; Perrier, 2013). Middle-class parents tend to engage in 'concerted cultivation' (Lareau, 2003), involving the obligation to invest extensive amounts of effort into monitoring and developing their children's learning and social skills. While the feeling of being under surveillance typifies intensive, middle-class mothering, working-class mothers also monitor and measure themselves against these ideals (Ponsford, 2011; 
Romagnoli and Wall, 2012). Mothers who occupy less advantaged social class positions, including young mothers, often feel the need to demonstrate respectability through consumption, while lacking the resources to do so (Banister et al., 2016; Ponsford, 2011; Skeggs, 2004). Yet intensive mothering is a global cultural script, viewed by many parents around the world as the 'proper' way of raising children (Faircloth and Gürtin, 2018). While differences in class, ethnicity and gender affect how parents internalise the norms of intensive mothering, it remains the "normative standard by which mothering practices and arrangements are evaluated' (Arendell, 2000: 1195).

There is a growing body of research that examines how mothers cope with intensification of mothering norms during financial hardship, illustrating how mothers practise thrift and self-sacrifice to display devotion to their families (Cappellini et al., 2014, 2019; Waight, 2019). While such research helps to understand how mothers cope during financial hardship, less is known about how mothers prepare for times of anticipated future resource scarcity. In this article, we explore how such preparations are undertaken by a sample of relatively affluent, intensive mothers from the UK who are preparing for envisaged disruption to supply-chains/food shortages following Brexit. Based on our findings and existing research on intensive mothers, we develop the concept of the 'survivalist intensive mother', defined as a mother who anticipates marketplace disruption and resource scarcity, prepares and develops the skills to manage, protect and conceal their behaviours, and makes discontinuous trade-offs to ensure the survival and wellbeing of their children, while maintaining everyday performances of motherhood.

\section{The Context: Britain's Exit from the EU}

The United Kingdom is described as a nation divided regarding the decision to withdraw from the European Union (EU), with families, social groups and even political parties internally divided regarding whether to continue to fight to 'remain' or work out how to 'leave' (Koller and Ryan, 2019). The United Kingdom joined the European Economic Community (EEC) in 1973, confirmed by referendum in 1975. This union was built on Britain's international voice being bolstered and optimism for a prosperous and peaceful future (Walsh, 2016). The EEC developed into the EU in 1992 through the Maastricht treaty, designed to integrate Europe's nations politically and economically, including united foreign policy, common citizenship rights and a single currency, the Euro (although this was not adopted in the UK).

In 2009, the Eurozone crisis beckoned austerity as a key policy across Europe, harkening an intensification of divisions between the UK and the EU. Although many UK citizens displayed a heightened attachment to EU membership, the UK Independence Party (UKIP), with its single policy to leave the EU, rose in prominence against this backdrop of economic unrest. In 2013, David Cameron pledged to hold an 'in-out' referendum, should the Conservatives win the 2015 UK general election. Subsequently, on 23 June 2016, the UK held a referendum on whether the UK should leave the EU and the option to leave passed by a slim majority: $51.9 \%$ to $48.1 \%$. The result set in motion considerable exit negotiations, with the then Prime Minister Theresa May invoking article 50 of the Treaty on European Union to formally give notice of intent to leave the EU. Britain was (initially) set to depart the EU on 30 March 2019. 
UK citizens became increasingly concerned that Brexit would be completed on a "nodeal' basis, creating fear of food and other shortages, due to a breakdown of UK-EU trading relations (Feng et al., 2017). UK food retailers, led by the British Retail Consortium (BRC), initially announced that consumers should not stockpile food in anticipation of such unfounded eventualities; with the Department for Exiting the European Union reinforcing this view (Hope, 2018). However, major grocery retailers wrote to the Government (backed by BRC) in January 2019 warning of 'significant disruption' to food supplies in the event of a no-deal Brexit (Butler, 2019). Subsequently, the emergent phenomenon of so-called Brexit prepping began to gather momentum; with one in five Britons reportedly stockpiling goods (The Guardian, 2019). Several online Brexit-prepping communities emerged; spaces where likeminded individuals could meet to seek reassurance and advice from others to aid their prepping (Wollaston, 2019).

\section{The Study}

In this article, we focus on interview data collected between January and April 2019 with 21 mothers actively engaging with Brexit prepping, recruited from online Brexitprepping communities. The mothers were purposively recruited (Patton, 2002) with approval of site moderators. The online communities (comprising 16,000 members) were described as 'non-political' spaces - strictly enforced by site moderators. Whereas the majority of our sample identified as 'Remainers', a small number backed Brexit, but both shared common concerns regarding post-Brexit food availability/disruption. The main recruiting criterion was to interview individuals who were prepping and, although not the initial intention of our recruitment, only women responded to our appeal for participants. Indeed, members of the online Brexit prepping communities were predominantly women - signalling the gendered nature of this activity. Participants had previously never formally practised prepping. It was the uncertainty surrounding food availability and how best to prepare for this that drove the women to join online communities for reassurance, to develop their prepping skills and to share best practice with likeminded others. To gain insight into the prepping community, a year-long non-participatory sensitising netnography (Kozinets, 2014) of the online communities was also undertaken (April 2018-April 2019). This allowed insight into the prepping community and glimpses of their prepping behaviours (informing questions posed during later interviews).

Given the secrecy of the prepping community, and the geographical spread of participants across the UK, interviews were conducted by phone or video-conference. Prior to interview, the women were encouraged to capture their preparations in a series of photographs via their smartphone. The photographs acted as a prompt during interviews to discuss what had been gathered and why, and where and how goods were stored. Interviews were semi-structured and explored broad themes covering prepping experiences (e.g. what prepping means to them; how they had decided what - and how - to store and practical decisions surrounding how long their 'stash' would last/how their stash was managed) and motivations and rationale (e.g. who they discussed prepping with; their partner's/children's reaction to their prepping; who they were prepping for). Participants were, however, able to raise issues which they felt pertinent to understand their prepping behaviours and activities. 
During interview, the women disclosed information they felt pertinent and comfortable to discuss. They self-identified as white British, heterosexual and middle class, although a small number of participants did not wish to offer finer demographic detail (e.g. occupations, their geographic location). The women were aged between 27 and 61, were in paid employment (with the exception of Emily, who was a stay-at-home parent) and lived with their male partner and children. Their children were aged between three and 20 years old (and all lived with them at home). Occupations ranged from teacher, charity worker, accountant and solicitor (with participants, therefore, indicating significant cultural and economic capital).

With the consent of participants, interviews were recorded and transcribed verbatim. The male lead author who conducted each interview was positioned as an 'outsider', with the researcher being perceived as neutral in gaining the trust of participants to share their experiences of motherhood in a non-judgemental setting. Each interview lasted between 60 and 90 minutes, with a gift-card offered to participants as a token of thanks for their participation. Ethical guidelines were closely followed, with this project holding university ethics board approval. We follow Braun and Clarke's (2006) thematic approach to data analysis. Each transcript was initially read and re-read by individual members of the research team. Notes and memos were exchanged which focused on developing a full understanding of each participant. Once this stage of analysis was complete, patterns across participants emerged, in an iterative manner. The women largely conceptualised meeting the needs of their children as their responsibility. Accordingly, we used the concept of intensive motherhood as a sensitising concept in our analysis.

First, we offer a sense of the rationale the mothers gave in making sense of their prepping activities. Second, we illustrate how participants break with elements of existing intensive motherhood ideology by means of invisible displays. Finally, we show how the food they plan to offer their children during times of disruption is often far from ideal, or healthy, contesting previous intensive motherhood research.

\section{Prepping as a ('Good') Mother's Duty}

Across our interviews, participants viewed the work of feeding the family as their own responsibility. This was a more pervasive enterprise than simply preparing meals, encapsulating a range of provisioning, storing and managing activities to ensure that there was enough food to eat, should their concerns be actualised. For example, participants often recounted sophisticated spreadsheet systems and inventories which detailed the contents of their 'stash', how various ingredients might contribute to weekly meal plans and information like best-before dates. They depicted highly gendered relations at home, with male partners largely absent from (and initially unsupportive of) their prepping behaviour, receding into the background of their efforts. While the women discussed how their partners 'tolerated' their prepping, participants saw it as their primary responsibility to meet the needs of their family. Food was framed by the women as a means to express love and as a mechanism to meet the sometimes-unique needs of their children (e.g. specific dietary requirements). To potentially deprive their children (particularly those with food intolerances) of access to such sustenance through their own poor planning/ preparation was characterised as 'bad' mothering, as Judy illustrates: 
Well, you think of the original hunter-gatherer - you're the hunter [to the male researcher] and I'm the gatherer. And that's what we do - we gather it, that's what mums do. I picked my daughter up from an exam the other day and I said don't let anyone tell you that I express love through food. But on the dashboard, there was a nice gluten-free ${ }^{1}$ chocolate bar, a punnet of strawberries, peas, because she loves podding some peas, as we call it, and some cherries. I said take your pick, but don't let anyone say that I express love through food! [laughing]. I think a big part of me, who I am as a mother, would be removed completely if I couldn't feed the family, so I do worry . . . It gives me a bit of peace of mind to know that she's cared for, taken care of. She won't starve and I won't feel like a crap mum.

This highly emotive concern to provide for their children was in part motivated through the women's framing of the child as 'innocent', a prominent feature of intensive mothering (Hays, 1996). Prepping became an activity to ensure children could be fed during times of envisaged difficulty, but also as means to ensure the child's safety in postimagined events (with many of the women envisaging scenes of civil unrest following, in their view, the inevitability of food shortages). Melanie explains:

To put myself or my kids into a position of not having enough food to eat, or to put ourselves in dangerous situations to find suitable food when people are fighting to get it? My family's more important to me than that, so I'm doing this for them and to keep them fed and safe.

In her interview Hannah also highlighted that potential food shortages and the societal violence/disruption which could ensue were in no way attributable to her (blameless) children. Hannah, like others, also acknowledged earlier experiences of food poverty:

My children have known poverty in the past. I will not let that happen again and I want to ensure that if, through no fault of their own, prices rise and we have to make tough financial decisions, that they will still eat.

Hannah enacts what Orgad (2009) refers to as the therapeutic discourse of the survivor. Although acknowledging a traumatic event (food poverty), she mobilises positive action to afford the peace of mind that she is taking personal responsibility for her family's well-being. It is important to highlight, however, that often the mothers did not want their children to 'have it too easy', recognising that a degree of managed struggle could be character building. For example, Anna reflects:

I grew up in poverty. I mean we lived from day to day, hand to mouth and 50p in the electricity meter. And if it ran out, we were in darkness. That was the simple fact of it. And I don't want my kids to experience that hardship. I don't mind them having a bit of a struggle, because I think that's good for your character, but I really do worry that if this goes back to like the threeday week, and the power cuts, that was a crap time.

Both Anna and Judy refer emotively to 'crap' motherhood: mothers who were not preparing sensibly for anticipated times of hardship and food scarcity. Sarah, although more extreme in view, attributed such 'bad' mothering practices to her fear that people outside the home would question her ability and competence to mother her children, should she not be able to offer them food: 'You start thinking are people going to ring social services 


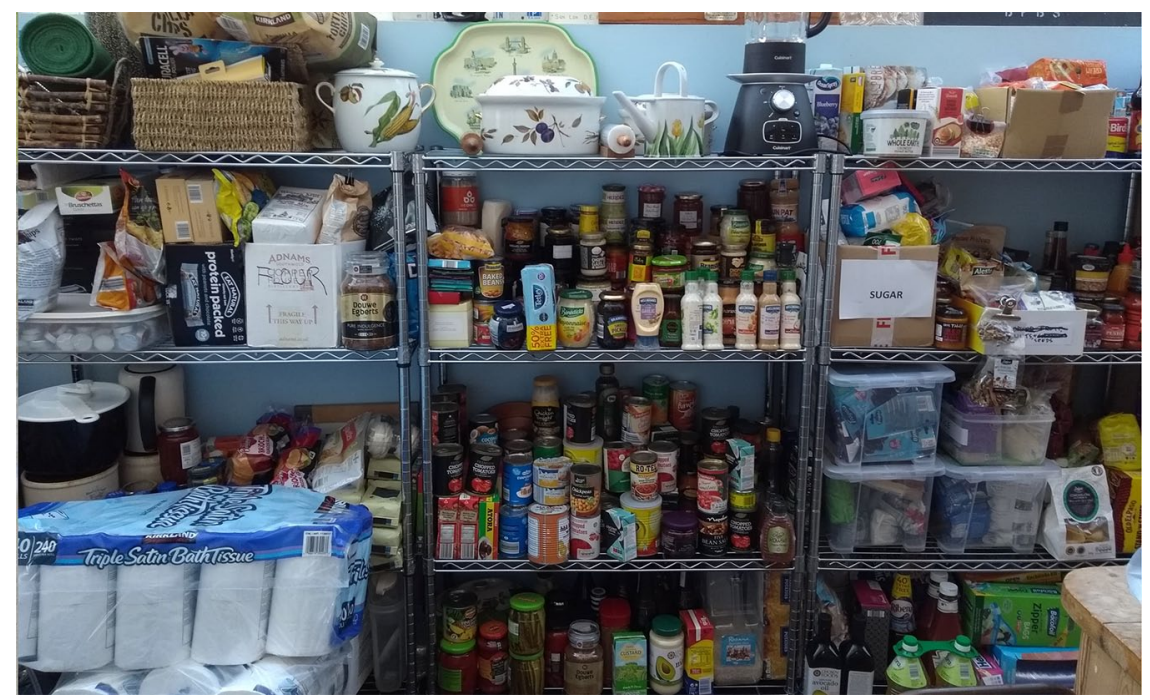

Figure I. Purpose built storage area.

because we have no food? Are people going to think that I'm not coping?' Sarah's concerns regarding the imagined future consequences of not meeting expectations is reflective of the motherhood display literature (Dermott and Seymour, 2011; Finch, 2007). Being seen by others, particularly other women, as a 'good' mother was important for our participants, yet their prepping activities remained highly secretive and guarded.

While mothers made links to financial difficulties to justify their prepping activities (e.g. Hannah was prepping for fear of post-Brexit price rises; Anna positioned herself as a 'survivor' of previous financial difficulty), it is important to stress that prepping was seen by participants as separate from financial savings or thrift (at the point of purchase, at least). Many participants discussed the high cost of prepping behaviours, particularly in relation to purchasing specialist equipment (e.g. vacuum packing devices/food dehydrators/food-grade storage containers) or the cost of food waste due to poor stock management and rotation (e.g. forgetting to use goods/waste emerging from rodent or other infestation). As middle-class mothers, participants could afford to purchase such equipment, which they saw as worthy investments to protect and manage their stash.

Prepping often became an all-encompassing means to invoke 'good' motherhood discourse. The mothers spent an inordinate amount of time adding to their stash, preparing designated, sometimes purpose-built, storage areas for their goods (e.g. in garages, lofts, on top of/underneath kitchen cupboards: see Figures 1 and 2). They invested time researching new methods to store and preserve food (e.g. pickling, dehydrating, sourcing store cupboard recipes and trialling these at mealtimes, becoming Brexit ready) and displayed their love for the family through calculating how much food and other items they would need should their fears be realised. While this often appeared overwhelming, the mothers did not begrudge the effort incurred, symptomatic of the selfless, labour intensive, self-sacrificing intensive mother (Hays, 1996; Lee et al., 2010), as Andrea explains: 


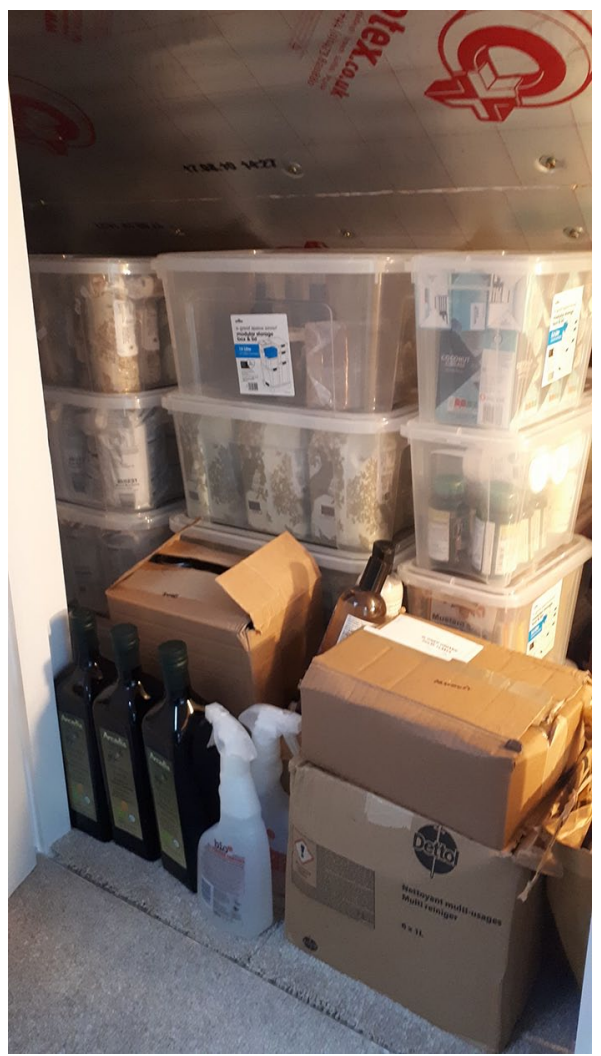

Figure 2. Storage containers in eaves full of rice, pasta, olive oil and cleaning products.

What I'm doing all takes time . . . from the effort I put into it, it costs, all my energies, it's vast. You've got to think what do we eat, on a day-to-day basis, what do we eat, how much of everything, for how long? Is one month enough, is six months? I've gone for the six months scenario, just to be safe. Right down to toothpaste, shampoos and toilet paper, you can't forget the toilet paper, making an inventory of what we go through and use . . . it becomes allencompassing and there's always the sense of do I need more? So, I go out and get more. I don't mind it though, I know I could usefully spend my free time doing other things, seeing friends, reading a book, but that's not what motherhood is about, is it? I'm doing it because that's what mums do, for the good of their kids.

\section{Invisible and Creative Displays of Mothering}

Mothering literature highlights the importance of displaying oneself as a 'good' mother (see James and Curtis, 2010), particularly in relation to feeding the family (Harman and Cappellini, 2015; O’Donohoe et al., 2013). However, being a good survivalist intensive mother involves a degree of managed invisibility, even secrecy, keeping prepping behaviours hidden for fear that others (outside the family) could find out about (and potentially 
steal) their stash, and fear that others may view them as neurotic. Anna reported feeling 'glad that we didn't tell people' to avoid becoming a target for friends, neighbours or thieves in an imagined post-Brexit food shortage: 'because who are they going to come to first? . . . It's not a bad idea to keep quiet.' The women sought to avoid suspicion from those in their social milieu, including supermarket delivery drivers who might have noticed their stockpiling, as Jane comments:

I worry that the TESCO delivery driver knows what I have, but it does get you in to that mindset, what will I do with the empty tin cans? You know, my neighbours might see what I've got [if food shortages are actualised] and come looking for things.

While intensive motherhood involves self-surveillance to ensure displays of good mothering illustrate dedication to their child's development (Budds et al., 2017), survivalist intensive motherhood brings a new layer of complexity, requiring mothers to keep their prepping behaviours secret, while maintaining their everyday mothering practices/ display. For example, rather than overtly bulk buying, Kelly would 'just buy a couple of things extra a month . . . an extra packet of pasta there, oh that's on offer, I'll grab some of those'. Sales promotions were often used to slowly and prudently build their stash (rather than bulk-buying goods in a short timeframe). Indeed, participants were highly critical of 'others' who resorted to bulk-buying, which implies poor planning and panic buying on their part, which our mothers wanted to distance themselves from. Our participants view their own behaviours as 'sensible', as part of the 'logic of the savvy shopper' (Campbell et al., 2019: 806), and do not want to draw attention to this seemingly laudable activity.

Yet the women acknowledged that as their stockpile grew, they would need to go to increasingly intensive efforts to avoid discovery. As well as necessitating significant space requirements, accumulating and managing their stockpile also meant finding creative ways to maintain its invisibility:

I'm certainly not advertising that I have food. What I've done, I'm not storing it all in one place, I've broken it down into smaller blocks. There's bits in the kitchen, bits in the garage, bits in the loft, tins under the floorboards in the front room, tins behind the bottom plinths under my kitchen cabinets. If I do get burgled then I'm just able to minimise the likelihood of losing the lot, assuming they stop looking for food when they find the first mini stash and don't start ripping up the floorboards! (Paula)

Many women, including Paula and Melanie, adopted the strategy of using multiple, hidden spaces such as the chimney (see Figure 3), under the floorboards, or behind the sofa to spread risk and minimise discovery. They often felt the need to ensure that their stash was kept secure for the longer-term good of their family, as Paula explains:

I've put a Night Lock on the front and back door, I bought that on Amazon, this little metal attachment that secures your door if someone tries to break in, and I bolt that up each night now, that's my new routine. I'm just getting into the habit of being more security-minded, particularly because I'm worried about my stash, which I think is a good thing to do anyway, to protect your family as much as you can. I think it's about insulating your family as much as you can. 


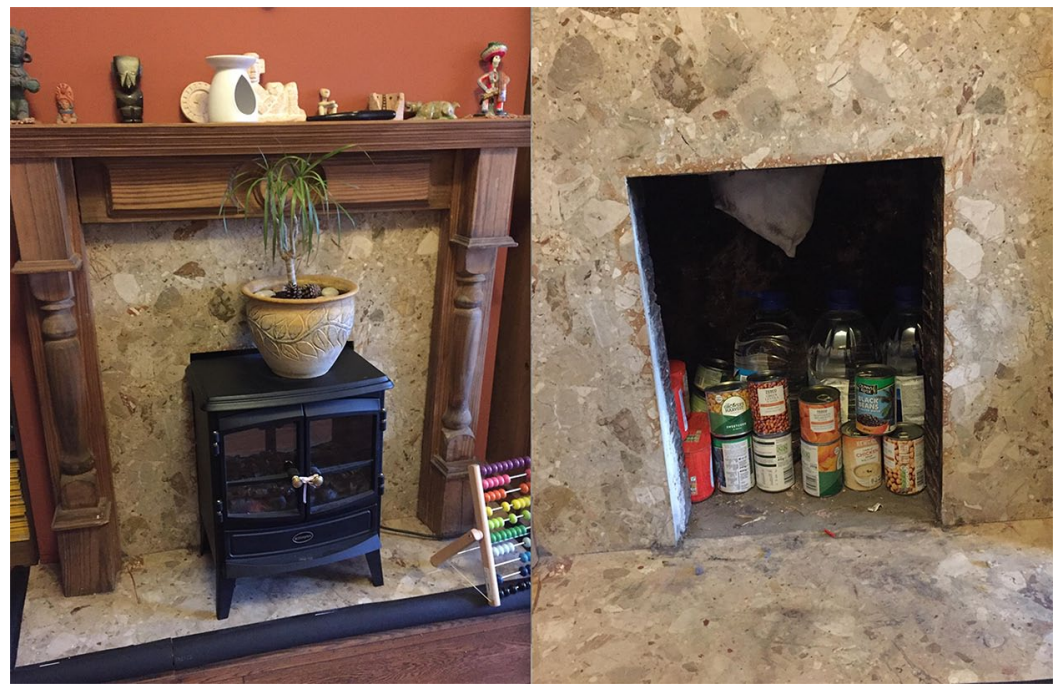

Figure 3. 'Stash' (tinned goods/bottles of water) hidden behind unused fireplace.

Paula's account illustrates how norms of intensive motherhood are heightened when combined with prepping, creating new mothering responsibilities to protect their stash and keep their family safe. Paula devotes extensive amounts of time, energy and resources to prepping behaviours, which she sees as an investment in the family's future safety and well-being: 'it's hard work, all this prep, and I don't want to run the risk of my efforts and hard work going down the toilet'.

Although invisible, the women viewed prepping behaviours as part of an 'ethic of care' for the family (Harman and Cappellini, 2015: 775), as Sarah highlights: 'I'm kind of doing my motherhood bit in secret, behind closed doors . . . This isn't something that I would shout about, but it's something that I feel I need to do as a good mum, a responsible mum.' Women like Sarah distinguished between everyday displays of good, intensive mothering and their invisible, yet all-encompassing prepping responsibilities:

I know people put things on Facebook, my mates online, they post about taking their kids to football, to netball or baking with them or just flashing the cash on them, tuition, extra lessons. That doesn't make me feel so great and I want to shout at them how ignorant they're being to the current state of things. Get some tins in! But I just sit there, secretly prepping. I don't need other people to know what I'm doing, it just gives me some inner peace, protecting, feeding, future-proofing for them. It's low key, even if it does take up all my time sourcing deals, preserving things, adding to the inventory, rotating the stock. It's a full-time job.

Although Sarah feels that prepping provides her with a private sense of 'inner peace' derived from ensuring her family's future well-being, it nevertheless places significant demands on her time and resources. Beneath the mundane displays of everyday 'good', middle-class mothering (Lareau, 2003; e.g. on Facebook, extra-curricular activities), women like Sarah work hard to develop new skills to manage their stash (sourcing deals, 
preserving food, keeping complex inventories and rotating stock to ensure minimal food waste).

At the point where prepping resulted in more structural family home changes (e.g. taking up floorboards/moving heavy items to concealed places) male partners were sometimes enrolled by the women to help with their prepping. Such effort was initially offered begrudgingly, with the men largely ambivalent towards their partner's behaviour. However, as the Brexit deadline loomed, and 'imagined' possibilities became increasingly likely, the women reported the more active involvement of their male partners. These more visible activities (at least within the family) drew the attention of children to Brexit prepping. Although younger children were quite easily shielded from this, older children often became aware of prepping, but were told not to disclose such action to others. These developing family secrets were not only framed as essential to protect their family from potential food scarcity post-Brexit, but also to protect from potential stigmatisation due to the non-mainstream nature of prepping, as Jane outlines:

Really, I'm more wary about who I tell, to be honest. If I've mentioned it to a couple of colleagues, it's in a jokey kind of way to be honest, 'oh yeah, I'm prepping for the apocalypse, ha ha hah!' kind of thing. People just think that's kind of funny.

As the women manage their hidden stash, they are actively hiding their behaviours from external audiences, yet privately 'displaying to themselves' that 'they are competent, caring mothers' (Harman and Cappellini, 2015: 776) but in doing so, also anticipate a future where their family 'survives'.

\section{Unhealthy Trade-Offs as Part of the Ethic of Care}

Intensive motherhood is underpinned by a moral discourse that renders mothers accountable for foodwork and ensuring children's development, for the good of the family and society (Budds et al., 2017; Cappellini et al., 2019). The women in our study had internalised their responsibility to provide a healthy diet for their children, yet they were also very aware that the types of food they were stockpiling were often in conflict with their relatively healthy everyday diets:

I'm just kind of conscious of them growing, they need to be fed. And they need to be fed well. They eat a lot of fruit and veg. Do you know what? If I can't get hold of that, that bothers me a bit. But what bothers me more is that they're full up and not hungry, so in these situations, ethics, values, morals, healthy eating, what have you, they go out of the window. We've got a load of dried stuff, and tinned stuff, and we just have to hope for the best to fill them up. (Anna)

As Anna explains, the women were concerned that fresh foods could not be stored easily for later consumption. Foods with a long shelf-life, such as dried and tinned foods, were acknowledged as lacking nutrition and as containing preservatives (features of foods they would not ordinarily offer their children). They perceived a trade-off, however, between prioritising the satisfaction of short-term hunger over the long-term health of their children in imaged post-Brexit disruption, as Sarah elaborates: 
My kids are my world and I've got to make sure there's food in their bellies. It might not be good food, you won't be able to get greens or fresh stuff, but it will be tinned stuff, frozen veg, chicken nuggets, Fray Bentos ${ }^{2}$ pies, they last forever. It's important they're full and it won't kill them for a bit while we wait things out. It's not the healthiest, but what can you do? . . I think it's a trade-off: hunger or quality food. Fresh food, it just doesn't keep.

Sarah's narrative shows how the women are still keen to demonstrate how their behaviours are about ensuring their child's well-being, by emphasising how fulfilling the basic need of hunger becomes the priority under extreme circumstances. As Sarah continues: 'if you can't go to the shops because of looting or shortages, rationing, your priorities should be to feed those little mouths, rubbish or otherwise'. The women neutralised their trade-offs as derived from a situation over which they had little control and by perceiving these measures as having minimal long-term effects on their children.

Previous research has shown that being a middle-class mother means making 'proper dietary choices for her children', with middle-class mothers distancing themselves from 'mothers from a lower social class' who give their children junk food (Harman and Cappellini, 2015: 777, 772). For the middle-class women in our study, foods they would normally distance themselves from, such as 'Pot Noodles, instant noodles, corned-beef' (and the aforementioned Fray Bentos pie) become legitimate sources of sustenance in times of resource scarcity. The women often drew on wartime nostalgia and survivalist discourse (Orgad, 2009), as Sarah explains: 'nutrition is important, but only to an extent. If it was good enough in the war, it's good enough now.' They took inspiration from some of the earliest 'celebrity chefs', like Marguerite Patten, a prominent wartime home economist, whose recipes used rations and mainly tinned/preserved goods, rather than contemporary chefs (e.g. Jamie Oliver), like the mothers in Harman and Cappellini's (2015) study.

In preparing for times of crisis women like Anna also saw it as part of their caring role to incorporate some unhealthy treats into their stockpile, to maintain morale:

I'd like to say you know what, I do have this little box of chocolates stashed away and it's a bit of a treat. I'd like to, I just want to mitigate. This is awful. We're having to think like this, and I think God you know they're like 16 and 14 and they are going through all this and it's really shit. And I don't want them to have this in their memory as children. I want them to have an idyllic, fun-filled childhood with little trauma.

To overcome these challenging times, they assume personal responsibility for protecting their children from trauma, by adopting a survivor mentality, which requires optimism and remaining positive in the face of adversity (Gill and Orgad, 2018). The women deemed themselves ultimately responsible not only for preventing hunger, but also 'mitigating' the psychological impact of food shortages on their children.

The women also perceived a time-based 'trade-off' derived from being sufficiently well prepared. They felt that time they invested in prepping would be recouped, enabling them to devote more time to their children when they needed the most protection and care (i.e. following the 'Brexit chaos'). Here the mothers report planning for this anticipated future using the community popular acronym 'SHTF' (shit hits the fan), as Emily explains: 
It makes me feel better knowing that I have a stash of food that will protect us for a couple of weeks, maybe a month. I don't need to spend days trying to find a loaf of bread or food for the kids when shit hits the fan, but I can devote that time to the children, playing with them, spending time with them, calming them down. That's what's important, the most important to me and prepping buys me that time with payback coming later.

Emily's quote illustrates how the women saw the time and effort they spent (invisibly) prepping for food shortages as an investment that would be offset by the 'payback' of being able to perform important emotional care work at a later point.

\section{Discussion}

In a world increasingly characterised by uncertainty and existential anxiety posed by an array of different threats (e.g. climate change, global financial crises, technological collapse, global pandemics), our research offers valuable insight into how this permeates the everyday realm of the family. Using the context of Brexit prepping, we explore how mothers shoulder much of the burden of ensuring their family's ongoing well-being, by gathering, preserving and managing their stockpile of provisions in anticipation of times of resource scarcity. As our findings illustrate, the mothers felt that providing food for the family was ultimately their responsibility, reiterating the gendered nature of responsibility for feeding the family (DeVault, 1991; Harman and Cappellini, 2015). Extending the concept of intensive mothering, this article introduces the concept of 'survivalist intensive mothering' to understand mothers' challenges in preparing for anticipated future marketplace disruption and resource scarcity.

The analysis shows how survivalist intensive mothering emerges when the powerful norms of intensive mothering combine with a growing sense of needing to be prepared, as part of a 'good' mother's responsibility. The mothers evoke the discourse of the survivor (Orgad, 2009) which helps them to reframe uncertain circumstances they may face, prompting the need for positive action to engage in prepping behaviours to provide for and protect their family (post-Brexit). However, we suggest that it is the combination of intensive mothering with the 'survivor' mentality that further embeds mothers in a mode of hyper-intensive mothering: survivalist intensive mothering. While many of the tenets of intensive motherhood were present in our participants' accounts (e.g. they were labour intensive, child-centred, involved self-sacrifice), we discern two key departures from their behaviours which depict survivalist intensive mothering.

First, survivalist intensive mothering necessitates the purposeful managed invisibility of prepping behaviour. Media and popular discourses focus on the 'hyperbolic eccentricities' of prepping (Campbell et al., 2019: 799), exacerbating the need to conceal prepping behaviours in the face of feared stigma. Additionally, fears over food security, as a result of anticipated shortages and aberrant social breakdown, colour the women's emotionally charged accounts of hiding food in old fireplaces and under kitchen cupboards. Such secretive behaviours are in contrast to everyday intensive mothering practices, in which mothers work to display good mothering practices to external audiences (Finch, 2007; Harman and Cappellini, 2015). Given the surveillance which surrounds 'good' parenting, and motherhood in particular, we argue that secrecy may be more widespread 
in broader performances of intensive motherhood (e.g. mothers who covertly hire personal tutors to aid their child's academic progress), which needs further investigation. Although hidden from external audiences, the women were creatively displaying 'to themselves' that they were 'competent, caring mothers' (Harman and Cappellini, 2015: 776). The 'display to self' that characterised the Brexit prepping mothers' accounts reflects the neoliberal political economy where the primary relationship is with the self, wrought through constant comparison with present and future-selves, in the context of real and imagined-others (Gill and Orgad, 2018).

Second, survivalist intensive mothering requires mothers to make discontinuous trade-offs in the ethics of care. Having internalised the middle-class norms of 'healthy eating' involved in everyday intensive mothering display (Harman and Cappellini, 2015), the mothers in our study were very aware that the tinned/convenience foods within their 'stash' would normally be perceived as markers of deviation from middle-class mothering. However, the mothers re-frame their private displays of prepping behaviour as a positive response to a crisis (Orgad, 2009) enabling them to prioritise the short-term satisfaction of hunger over healthy eating. The mothers also frame prepping as playing a mitigating role that could offset the anticipated psychological impact of marketplace disruption to their family. Prepping behaviours are viewed as a private investment that will enable them to devote more time and psychological care to their children when they need it most. We suggest that mothers are likely to make such discontinuous trade-offs in other aspects of their role (e.g. prioritising extra-curricular activities, fuelled through snatched ready-meals in place of healthy sustenance and family meal time).

We suggest that survivalist intensive mothering emerges as a complex 'anticipatory' and 'pathologised' subjectivity (Barker, 2019: 485-486), born out of 'regimes of anticipation' that prompt responsible citizens to be prepared for potential crises or disruption (Adams et al., 2009: 249). Survivalist intensive mothers must be attuned to potential crises and 'voluntarily self-regulate' to ensure that they are well prepared, safeguarding their family's self-sufficiency and survival (Barker, 2019: 485). However, part of the reason, we argue, that the mothers in our sample hide their prepping behaviours is not just to protect their 'stash' (for fear others would take it), but also to avoid being pathologised as deviating from the norms of everyday intensive motherhood, by being labelled as eccentric or neurotic mothers.

It is important to recognise that our participants identified as middle-class mothers. As such, they are relatively well positioned to afford the financial investment in resources (pertaining to the cost of their stockpile and the necessary specialist equipment, such as canning machines and food dehydrators) and the physical space to store, manage and hide their preparations. The ideology of intensive motherhood is, however, not confined to the middle class (Romagnoli and Wall, 2012). Mothers occupying more precarious positions may well experience heightened tensions if they, too, struggle to meet the norms of survivalist intensive mothering. We recognise the potential class-based inequalities evident in prepping, which need further exploration, particularly since recent COVID-19 disruption to the marketplace (and food shortages which ensued) may well encourage individuals to be better prepared for uncertain times.

Finally, while our ongoing netnographic work within the online prepping sites suggests that preppers now feel their behaviours are vindicated, there is still a sense among 
preppers that their stash must remain hidden, suggesting that survivalist intensive motherhood will continue to require some elements of secrecy until society legitimises prepping activities more widely. Our study unpicks these complexities in the context of intensive parenting, illustrating that further research in this area is useful in these, seemingly permanent, uncertain times.

\section{Funding}

The authors received no financial support for the research, authorship and/or publication of this article.

\section{ORCID iDs}

Ben Kerrane (iD https://orcid.org/0000-0003-2114-5965

Katy Kerrane (iD) https://orcid.org/0000-0002-8447-5673

\section{Notes}

1. One of Judy's daughters has coeliac disease.

2. Fray Bentos pies are a highly processed tinned meat product and have historical origins as food of the working class (Psetizki, 2008).

\section{References}

Adams A, Murphy M and Clarke A (2009) Anticipation: Technoscience, life, affect, temporality. Subjectivity 28: 246-265.

Arendell T (2000) Conceiving and investigating motherhood: The decade's scholarship. Journal of Marriage and Family 62(4): 1192-1207.

Banister E, Hogg MK, Budds K, et al. (2016) Becoming respectable: Low-income young mothers, consumption and the pursuit of value. Journal of Marketing Management 32(7/8): 652-672.

Barker K (2020) How to survive the end of the future: Preppers, pathology, and the everyday crisis of insecurity. Transactions of the Institute of British Geographers 45(2): 483-496.

Braun V and Clarke V (2006) Using thematic analysis in psychology. Qualitative Research in Psychology 3(2): 77-101.

Budds K, Hogg M, Banister E, et al. (2017) Parenting agendas: An empirical study of intensive mothering and infant cognitive development. The Sociological Review 65(2): 336 -352.

Butler S (2019) No-deal Brexit would mean shortages and price rises, say retailers. The Guardian, 28 January. Available at: https://www.theguardian.com/business/2019/jan/28/no-deal-brexitprice-rises-retailers-sainsburys-asda-ms-coop (accessed 2 February 2019).

Campbell N, Sinclair G and Browne S (2019) Preparing for a world without markets: Legitimizing strategies of preppers. Journal of Marketing Management 35(9/10): 798-817.

Cappellini B, Harman V, Marilli A, et al. (2019) Intensive mothering in hard times: Foucauldian ethical self-formation and cruel optimism. Journal of Consumer Culture 19(4): 469-492.

Cappellini B, Marilli A and Parsons E (2014) The hidden work of coping: Gender and the micropolitics of household consumption in times of austerity. Journal of Marketing Management 30(15-16): 1597-1624.

Dermott E and Miller T (2015) More than the sum of its parts? Contemporary fatherhood policy, practice and discourse. Families, Relationships and Societies 4(2): 185-195.

Dermott E and Seymour E (2011) Displaying Families: A New Concept for the Sociology of Family Life. Basingstoke: Palgrave. 
DeVault M (1991) Feeding the Family. London: The University of Chicago Press.

Faircloth C and Gürtin ZB (2018) Fertile connections: Thinking across assisted reproductive technologies and parenting culture studies. Sociology 52(5): 983-1000.

Feng S, Patton M, Binfield J, et al. (2017) 'Deal' or 'no deal'? Impacts of alternative post-Brexit trade agreements on UK agriculture. EuroChoices 16(3): 27-33.

Finch J (2007) Displaying families. Sociology 41(1): 65-81.

Gill R and Orgad S (2018) The amazing bounce-backable woman: Resilience and the psychological turn in neoliberalism. Sociological Research Online 23(2): 477-495.

Harman V and Cappellini B (2015) Mothers on display: Lunchboxes, social class and moral accountability. Sociology 49(4): 764-781.

Hays S (1996) The Cultural Contradictions of Motherhood. New Haven, CT: Yale University Press.

Henderson AC, Harmon SM and Houser J (2010) A new state of surveillance? An application of Michel Foucault to modern motherhood. Surveillance \& Society 7(3-4): 231-247.

Hope K (2018) My Brexit box: The people stockpiling food. BBC News Online, 9 October. Available at: https://www.bbc.co.uk/news/business-46111085 (accessed 14 November 2018).

James A and Curtis P (2010) Family displays and personal lives. Sociology 44(6): 1163-1180.

Kehily MJ and Thomson R (2011) Displaying motherhood. In: Dermott E and Seymour J (eds) Displaying Families: A New Concept for the Sociology of Family Life. Basingstoke: Palgrave, $61-80$.

Koller V and Ryan J (2019) A nation divided. In: Hart C (ed.) Cognitive Linguistics and Textual Analysis: From Poetics to Politics. Edinburgh: Edinburgh University Press, 131-156.

Kozinets R (2014) Netnography: Redefined. London: SAGE.

Lareau A (2003) Unequal Childhoods: Class, Race and Family Life. Berkeley, CA: University of California Press.

Lee E, Macvarish J and Bristow J (2010) Editorial: Risk, health and parenting culture. Health, Risk and Society 12(4): 293-300.

Miller T (2005) Making Sense of Motherhood. Cambridge: Cambridge University Press.

Mills M (2019) Preparing for the unknown . . . unknows: 'Doomsday' prepping and risk anxiety in the United States. Journal of Risk Research 22(10): 1267-1279.

O'Donohoe S, Maclaran P, Hogg M, et al. (eds) (2013) Motherhoods, Markets and Consumption. London: Routledge.

Orgad S (2009) The survivor in contemporary culture and public discourse: A genealogy. The Communication Review 12(2): 132-161.

Patton M (2002) Qualitative Research \& Evaluation Methods. London: SAGE.

Perrier M (2013) Middle-class mothers' moralities and 'concerted cultivation': Class others, ambivalence and excess. Sociology 47(4): 655-670.

Ponsford R (2011) Consumption, resilience and respectability amongst young mothers in Bristol. Journal of Youth Studies 14: 541-560.

Psetizki V (2008) Uruguay serves up slice of history. BBC News online, 28 October. Available at: http://news.bbc.co.uk/1/hi/world/americas/7682670.stm (accessed 22 February 2018).

Romagnoli A and Wall G (2012) 'I know I'm a good mom': Young, low-income mothers' experiences with risk perception, intensive parenting ideology and parenting education programmes. Health, Risk and Society 14(3): 273-289.

Shirani F, Henwood K and Coltart C (2012) Meeting the challenges of intensive parenting culture: Gender, risk management and the moral parent. Sociology 46(1): 25-40.

Skeggs B (2004) Class, Self, Culture. London: Routledge. 
The Guardian (2019) Britons have spent $£ 4$ bn stockpiling goods in case of no-deal Brexit. The Guardian, 12 August. Available at: https://www.theguardian.com/politics/2019/aug/12/britons-have-spent-4bn-stockpiling-goods-in-case-of-no-deal-brexit (accessed 15 August 2019).

Waight E (2019) Mother, consumer, trader: Gendering the commodification of second-hand economies since the recession. Journal of Consumer Culture 19(4): 532-550.

Wall G (2010) Mothers' experiences with intensive parenting and brain development discourse. Women's Studies International Forum 33: 253-263.

Wall G (2013) 'Putting family first': Shifting discourses of motherhood and childhood in representations of mothers' employment and child care. Women's Studies International Forum 40: $162-171$.

Walsh J (2016) Britain's 1975 Europe referendum: What was it like last time? The Guardian, 25 February. Available at: https://www.theguardian.com/politics/2016/feb/25/britains-1975-europe-referendum-what-was-it-like-last-time (accessed 15 August 2019).

Wollaston S (2019) 'I don't trust the government to look after me or my dog': Meet the Brexit stockpilers. The Guardian, 14 January. Available at: https://www.theguardian.com/politics/2019/jan/14/i-dont-trust-the-government-to-look-after-me-or-my-dog-meet-the-brexitstockpilers (accessed 16 January 2020).

Ben Kerrane is Professor of Marketing at Manchester Metropolitan University Business School. His research interests include family consumption, fatherhood, childhood, gender relations and consumer socialisation. He has presented his research to a range of audiences and has published in European Journal of Marketing, Journal of Business Research, Studies in Higher Education, Journal of Marketing Management and Advances in Consumer Research.

Katy Kerrane is Lecturer in Marketing at University of Liverpool Management School. Her research interests revolve around family consumption, motherhood, gender and ethnicity. Her doctoral research explored the experiences of South Asian mothers in the UK, focusing on motherhood, gender identity and consumption. She has presented her research to a range of academic audiences (e.g. British Sociological Association, European Advances in Consumer Research) and has published in the European Journal of Marketing.

Shona Bettany is Professor of Marketing at Huddersfield Business School, University of Huddersfield. She is a consumer ethnographer focusing on consumer culture in all its guises but more specifically on contemporary consumption and the family. She has presented her research to the US and European meetings of the Association for Consumer Research and has published in Advances in Consumer Research, Consumption, Markets and Culture, Marketing Theory, Journal of Business Research, Journal of Marketing Management and the European Journal of Marketing.

David Rowe is a doctoral researcher at the University of Leeds undertaking a collaborative project with the History of Advertising Trust (HAT). His doctoral research explores sexual health advertising and promotion by analysing the use of language and images to reveal how advertisers have created a position of authority to guide discourses of contagion around sexual health. He has presented his research to a range of audiences (Macromarketing Conference, Chicago; Association for Consumer Research, Baltimore) and published in Advances in Consumer Research.

Date submitted January 2021

Date accepted January 2021 